\title{
PENGARUH PENAMBAHAN ALKANOLAMIDA TERHADAP KARAKTERISTIK PEMATANGAN DAN KEKERASAN VULKANISAT KARET ALAM BERPENGISI KAOLIN
}

\author{
Indah M.S. Sitorus, Yudha Widyanata, Indra Surya \\ Departemen Teknik Kimia, Fakultas Teknik, Universitas Sumatera Utara, \\ Jl almamater Kampus USU Medan 20155, Indonesia. \\ Email : indah.maulina17@gmail.com
}

\begin{abstract}
Abstrak
Dengan menggunakan system vulkanisasi sulfur terakselarasi semi effisien, penelitian mengenai pengaruh penambahan alkanolamida tehadap karateristik pematangan dan kekerasan Vulkanisat karet alam berpengisi kaolin telah dilakukan. Alkanolamida dihasilkan dari Refined Bleached Deodorized Palm Stearin (RBDPS) direaksikan dengan dietanolamin. Alkanolamida dimasukkan kedalam kompon-kompon karet alam yang berpengisi kaolin dengan kadar 1,0; 3,0; 5,0; 7,0 Bagian per-Seratus Karet (bsk). Alkanolamida mempersingkat waktu scorch dan waktu pematangan optimum dari karet. Alkanolamida juga menyebabkan peningkatan perbedaan tork, modulus tensile, kerapatan sambung silang, dan kekerasan dengan penambahan hingga 5,0 bsk alkanolamida, kemudian menurun bersamaan dengan penambahan alkanolamida yang lebih lanjut .
\end{abstract}

Kata kunci : alkanolamida, waktu pematangan, waktu scorch, sambung silang, vulkanisat karet alam, kaolin

\begin{abstract}
By using a semi-efficient sulphur accelerated vulcanization system, an investigation of the effect of alkanolamide on cure characteristics and hardness properties of kaolin-filled natural rubber compounds was carried out. Alkanolamide was synthesized from Refined Bleached Deodorized Palm Stearin (RBDPS) and diethanolamine. Alkanolamide was incorporated into the kaolin filled-natural rubber compound at 1.0; 3.0; 5.0 and 7.0 Parts per-Hundred RubbeR (phr). It was found that alkanolamide gave shorter scorch time and cure time. Alkanolamide also exhibited higher torque different, crosslink density, and hardnessup to $5.0 \mathrm{phr}$ and then decreased with further increasing the loading of alkanolamide.
\end{abstract}

Keywords : alkanolamide, cure time, scorch time, crosslink density, vulcanizate natural rubber, kaolin

\section{Pendahuluan}

Vulkanisasi adalah reaksi sambung silang (crosslinking) molekul- molekul karet oleh sulfur (belerang), sehingga dihasilkan suatu vulkanisat karet yang elastis dan kuat. Keelastisan dan kekuatan karet alam dapat ditingkatkan lagi dengan cara menambahkan pengisi penguat (reinforcing filler) kedalam karet tersebut. Pengisi dan penguat yang banyak digunakan dalam industri karet adalah kaolin dan carbon black. Kedua pengisi penguat ini memiliki sifat kimia permukaan yang berbeda satu dengan yang lainnya. Setiap jenis pengisi memberikan sifat-sifat tertentu kepada karet akibat dari permukaan kimianya yang sangat spesifik. Dibandingkan dengan karbon black, pengisi penguat dari kaolin memiliki permukaan yang sangat mudah menyerap air. Kehadiran gugus-gugus silanol, menyebabkan permukaan kaolin menjadi berkutup (polar) dan bersifat asam sehingga mempengaruhi reaksi vulkanisasi/ pematangan.
Gugus silanol ini relatif tidak kompatibel (incompatible) dengan karet alam, sehingga interaksi antara karet dengan pengisi menjadi lemah. Disebabkan oleh sifat kimia permukaan yang lebih berkutub dan berhidrat, maka kaolin merupakan pengisi alternatif yang kurang memuaskan. Suatu alternatif untuk meningkatkan reaktivitas dari pengisi penguat kaolin terhadap karet alam yaitu dengan menggunakan alkanolamida turunan minyak sawit sebagai bahan penyerasi. Molekulmolekul alkanolamida tersebut memiliki sifat polar dan non polar, dimana rantai hidrokarbon yang panjang bersifat polar sedangkan gugus amidanya bersifat sangat polar. Penelitian ini meneliti Pengaruh penambahan Alkanolamida terhadap karakteristik pematangan dan kekerasan dari vulkanisat karet alam berpengisi kaolin, dengan menggunakan sistem vulkanisasi sulfur terekstraksi semi-efisien $[2,4]$. 


\section{Teori}

Vulkanisasi adalah suatu proses dimana molekul karet yang linier mengalami reaksi sambung silang sulfur (sulfur-crosslinking) sehingga menjadi molekul polimer yang membentuk rangkaian tiga dimensi. Reaksi ini merubah karet yang bersifat plastis (lembut) dan lemah menjadi karet yang elastis, keras dan kuat. Vulkanisasi juga dikenal dengan proses pematangan (curing/cure), dan molekul karet yang sudah tersambung silang (crosslinked rubber) dirujuk sebagai vulkanisat karet (rubber vulcanizate). Vulkanisat karet tidak lagi bersifat lengket (tacky), tidak melarut tetapi hanya mengembang didalam pelarut organik tertentu [6].

\section{Metodologi Penelitian}

Tabel 1 menunjukkan bahan yang digunakan untuk sistem vulkanisasi sulfur teraksekerasi semi-effisien. Pembuatan dietanolamida dilakukaan dengan meraksikan RBDPS dengan dietanolamin pada tekanan atmosfir. Sebanyak 91,6 gram RBDPS dan 42,16 gram dietanolamin dimasukkan ke dalam labu yang berukuran 1 liter. Penggunaan penambahan katalis Natrium Metoksida yang terlebih dahulu telah dilarutkan dalam metanol (10 gram: 40 $\mathrm{ml}$ ) bertujuan untuk mempercepat proses reaksi amidasi. Campuran bahan tersebut kemudian diaduk selama 5 jam pada suhu $70-80^{\circ} \mathrm{C}$. Hasil dari reaksi tersebut kemudian diekstraksi dengan menggunakan larutan dietileter dan larutan $\mathrm{NaCl}$ jenuh di dalam corong pisah. Karena sifat dari dietanolamida yang tidak larut dalam larutan garam, tetapi dapat larut dalam larutan yang bersifat non-polar maka secara otomatis alkanolamida akan larut dalam dietileter. Pemisahan hasil ektraksi dilakukan berdasarkan sifat dari kedua larutan antara dietileter dan larutan $\mathrm{NaCl}$ jenuh yang tidak saling bercampur menyebabkan terbentuknya dua lapisan. Lapisan atas merupakan campuran dietileter yang melarutkan alkanolamida, maka lapisan tersebut disahkan kemudian dirotary evaporator untuk memperoleh alkanolamida.

Pengujian bengkak pada vulkanisatvulkanisat dilakukan dalam toluen berdasarkan ISO 1817. Potongan-potongan yang akan di uji (30 mm x $5 \mathrm{~mm}$ x $2 \mathrm{~mm}$ ) di timbang menggunakan timbangan elektrik dan di bengkakkan didalam toluen hingga kesetimbangan, yang mana memakan waktu selama 72 jam pada temperatur ruangan. Sampel-sampel dikeluarkan dari cairan, toluen yang masih ada di permukaan sampel dihilangkan dan ditimbang. Sampel-sampel tersebut lalu dikeringkan di dalam oven pada temperatur $60^{\circ} \mathrm{C}$ sampai berat konstan didapat. Hasil pembengkakan digunakan untuk menghitung berat molekul antara 2 buah sambung silang (Mc) dengan menggunakan persamaaan Flory-Rehner :

$$
\begin{aligned}
& M_{c}=\frac{-\rho_{p} V_{s} V_{r}^{1 / 3}}{\ln \left(1-V_{r}\right)+V_{r}^{2}} \\
& V_{r}=\frac{1}{1+Q_{m}} \ldots \ldots \ldots \ldots \ldots
\end{aligned}
$$

Dimana $\rho$ adalah kerapatan karet $(\rho$ dari karet alam $\left.=0,92 \mathrm{~g} / \mathrm{cm}^{3}\right), V_{s}$ adalah volum molar toluen $\left(V_{s}=106,4 \mathrm{~cm}^{3} / \mathrm{mol}\right), V_{r}$ merupakan fraksi volum dari polimer pada sampel yang membengkak, $Q_{m}$ merupakan peningkatan berat dari campuran di dalam toluene dan $\chi$ merupakan parameter interaksi antara jaringan karet dengan pelarut $(\chi$ dari karet alam $=0,393$ ).

Digunakan Karet Alam grade SMR L. Bahan komponding yang lain adalah sulfur, Zink Oxide, Asam Stearat, N-isopropyl-N' phenyl-p-phenylenediamine

(IPPD), Benzothiazolil disulfide (MBTS).

Senyawa karet alam disediakan menurut resep sistem vulkanisasi semieffisien. Tipikal resepnya dapat dilihat pada tabel 1. Pencampuran karet alam dan bahanbahan lainnya dilakukan pada two-roll-mill. Pencampuran karet alam dengan bahanbahan lainnya dilakukan secara bertahap \pm 65-75 ${ }^{\circ} \mathrm{C}$. Kemudian hasil pencampuran berupa lembaran tersebut dimasukkan ke dalam freezer pada suhu $\pm 21-25{ }^{\circ} \mathrm{C}$ selama \pm 24 jam.

Pengujian waktu pematangan optimum dilakukan dengan menggunakan Monosanto Oscillating-Disk Rheometer dengan suhu 150 oC. Vulkanisasi yang dilakukan mengunakan KAO Tech hot press pada suhu $150{ }^{\circ} \mathrm{C}$ dengan waktu pematangan $t_{90}$ yang telah diperoleh dari data pengujian waktu vulkanisasi/ pematangan optimum. Pengukuran Kekerasan Vulkanisat dilakukan berdasarkan ASTM D 2240 dengan menggunakan Durometer Shore A. 
Tabel 1. Sistem vulkanisasi sulfur terakselerasi semi-effisien

\begin{tabular}{|c|l|c|c|c|c|c|}
\hline No & Nama Bahan & $\begin{array}{c}\text { Kompon } \\
\text { A (bsk)* }\end{array}$ & $\begin{array}{c}\text { Kompon } \\
\mathrm{B}(\mathrm{bsk})^{*}\end{array}$ & $\begin{array}{c}\text { Kompon } \\
\mathrm{C}(\mathrm{bsk})^{*}\end{array}$ & $\begin{array}{c}\text { Kompon } \\
\mathrm{D}(\mathrm{bsk})^{*}\end{array}$ & $\begin{array}{c}\text { Kompon } \\
\text { E (bsk)* }\end{array}$ \\
\hline 1 & Karet alam & 100,0 & 100,0 & 100,0 & 100,0 & 100,0 \\
\hline 2 & ZnO & 5,0 & 5,0 & 5,0 & 5,0 & 5,0 \\
\hline 3 & Asam stearat & 3,0 & 3,0 & 3,0 & 3,0 & 3,0 \\
\hline 4 & MBTS & 2,0 & 2,0 & 2,0 & 2,0 & 2,0 \\
\hline 5 & IPPD & 2,0 & 2,0 & 2,0 & 2,0 & 2,0 \\
\hline 6 & Sulfur & 2,0 & 2,0 & 2,0 & 2,0 & 2,0 \\
\hline 7 & Kaolin & 30 & 30 & 30 & 30 & 30 \\
\hline 8 & Alkanolamida & 0 & 1 & 3 & 5 & 7 \\
\hline
\end{tabular}

* bagian per seratus karet alam (bsk)

Pengujian waktu pematangan optimum dilakukan dengan menggunakan Monosanto Oscillating-Disk Rheometer dengan suhu 150 oC. Vulkanisasi yang dilakukan mengunakan KAO Tech hot press pada suhu $150{ }^{\circ} \mathrm{C}$ dengan waktu pematangan $t_{90}$ yang telah diperoleh dari data pengujian waktu vulkanisasi/ pematangan optimum. Pengukuran Kekerasan Vulkanisat dilakukan berdasarkan ASTM D 2240 dengan menggunakan Durometer Shore A.

\section{Hasil dan Pembahasan}

Hasil dari pembuatan alkanolamida dibuktikan melalui bilangan gelombang yang terbentuk dari gugus karbonil amida yang diperlihatkan pada gambar 1, dimana munculnya pita serapan pada bilangan gelombang C-N (1558 $\left.\mathrm{cm}^{-1}\right)$. Pada bilangan gelombang daerah $3356 \mathrm{~cm}^{-1}$ menunjukkan adanya vibrasi gugus $\mathrm{OH}$. Pada bilangan gelombang $1069 \mathrm{~cm}-1$ yang merupakan vibrasi stretching C-O. Pada bilangan gelombang 717 merupakan $-(\mathrm{CH} 2)_{\mathrm{n}}$ yang merupakan rantai hidrokarbon alkil rantai panjang [3]

Pengaruh alkanolamida terhadap Karakteristik Pematangan Kompon Karet Alam berpengisi Kaolin ditunjukkan pada tabel 2 . Diperlihatkan bahwa waktu scorch dan waktu pematangan semakin singkat dengan bertambahnya penambahan alkanolamida pada kompon karet berpengisi silica. Hal ini kemungkinan disebabkan karena alkanolamida bertindak sebagai bahan yang membantu atau berkontribusi positif terhadap proses pematangan (co-curing agent), dimana gugus amina dari alkanolamida yang basa dapat meningkatkan derajat keasaman $(\mathrm{pH})$ dari kompon karet alam sehingga menyebabkan percepatan pematangan kompon karet tersebut. Setiap bahan yang lebih bersifat basa akan mempercepat proses pematangan kompon karet, karena bahan-bahan yang bersifat asam dapat melambatkan (retardasi) pengaruh dari bahan pencepat (accelerator) [1].

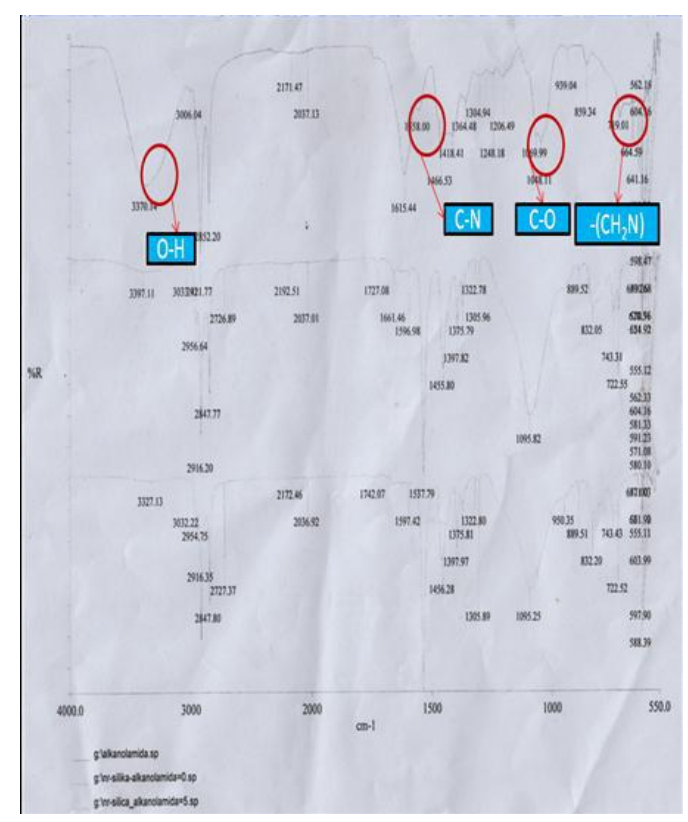

\section{Gambar 1. FT-IR alkanolamida}

Pengaruh alkanolamida terhadap Karakteristik Pematangan Kompon Karet Alam berpengisi Kaolin ditunjukkan pada tabel 2 . Diperlihatkan bahwa waktu scorch dan waktu pematangan semakin singkat dengan bertambahnya penambahan alkanolamida pada kompon karet berpengisi kaolin. Hal ini kemungkinan disebabkan karena alkanolamida bertindak sebagai bahan yang membantu atau berkontribusi positif terhadap proses pematangan (co-curing agent), dimana gugus amina dari alkanolamida yang basa dapat meningkatkan derajat keasaman $(\mathrm{pH})$ dari kompon karet alam sehingga menyebabkan percepatan pematangan kompon karet tersebut. Setiap bahan yang lebih bersifat basa akan 
mempercepat proses pematangan kompon karet, karena bahan-bahan yang bersifat asam dapat melambatkan (retardasi) pengaruh dari bahan pencepat (accelerator) [1].

Penambahan alkanolamida dengan kadar hingga 5,0 bagian per-seratus karet (bsk). ke dalam kompon Karet Alam berpengisi kaolin menghasilkan kompon karet alam berpengisi kaolin dan alkanolamida dengan nilai perbedaan Tork (Tork maksimum - Tork minimum) yang semangkin meningkat. Hal ini dapat disebabkan, alkanolamida dapat bertindak sebagai bahan yang membantu proses atau reaksi sambung silang (curative agent), yaitu dapat membentuk sambung silang tambahan, baik sambung silang secara kimia maupun sambung silang fisikal antara kaolin dengan karet alam. Penambahan sambungsilang ini menyebabkan peningkatan kerapatan sambung silang vulkanisat karet [5]. Sedangkan total kerapatan sambung silang secara relatif dapat diukur dari nilai perbedaan tork (Tork maksimum - Tork minimum). Pengaruh alkanolamida tersebut ditunjukkan pada Tabel 2. Penambahan alkanolamida dengan kadar lebih tinggi dari 5,0 bsk. menyebabkan nilai perbedaan Tork (Tork maksimum - Tork minimum) dari vulkanisat karet alam berpengisi tersebut menjadi menurun.

Tabel 2. Karakteristik Pematangan Kompon Karet Alam Berpengisi Kaolin dan Alkanolamida

\begin{tabular}{|l|c|c|c|c|c|}
\hline \multirow{2}{*}{\begin{tabular}{|l}
\multirow{2}{*}{ Ciri Pematangan } \\
\cline { 2 - 6 }
\end{tabular}} & \multicolumn{5}{|c|}{ Kompon Karet Alam Berpengisi Kaolin dan Alkanolamida } \\
\cline { 2 - 6 } & $\begin{array}{c}\text { KAO-I } \\
\text { wakt }\end{array}$ & $\begin{array}{c}\text { KAO-II } \\
1.0 \mathrm{bsk}\end{array}$ & $\begin{array}{c}\text { KAO-III } \\
3.0 \mathrm{bsk}\end{array}$ & $\begin{array}{c}\text { KAO-IV } \\
5.0 \mathrm{bsk}\end{array}$ & $\begin{array}{c}\text { KAO-V } \\
7.0 \mathrm{bsk}\end{array}$ \\
\hline waktu scorch, menit & 5.94 & 4.45 & 3.71 & 2.98 & 1.47 \\
\hline $\mathrm{t}_{90}$, menit & 9.89 & 7.61 & 6.31 & 5.4 & 3.38 \\
\hline tork maksimum, dN.m & 5.34 & 6.49 & 6.59 & 7.57 & 7.21 \\
\hline tork minimum, dN.m & 0.03 & 0.13 & 0.11 & 0.03 & 0.09 \\
\hline tork (maks.-min.), dN.m & 5.31 & 6.36 & 6.48 & 7.54 & 7.12 \\
\hline
\end{tabular}

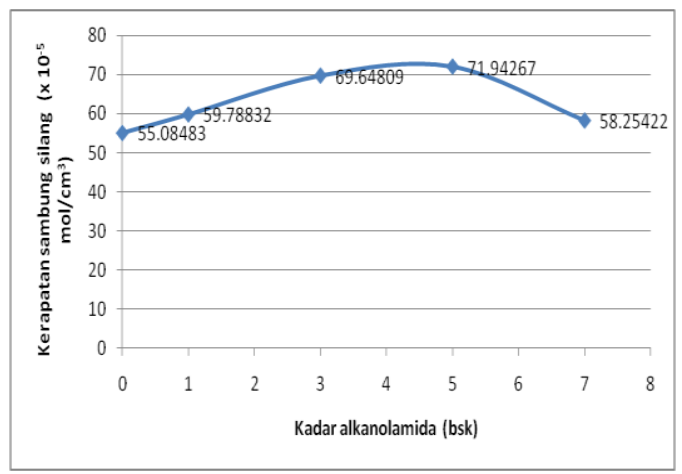

Gambar 2. Kerapatan sambung silang vulkanisat karet alam berpengisi kaolin dan alkanolamida

Gambar 2 menunjukkan kerapatan sambung silang vulkanisat karet berpengisi tersebut meningkat dengan ditambahkannya alkanolamida ke dalam kompon karet alam berpengisi kaolin hingga kadar 5,0 bsk., penambahan yang lebih banyak menyebabkan kerapatan sambung silang menjadi turun.

Alkanolamida juga mempengaruhi kekerasan vulkanisat karet alam berpengisi kaolin ditunjukkan pada gambar 3 .

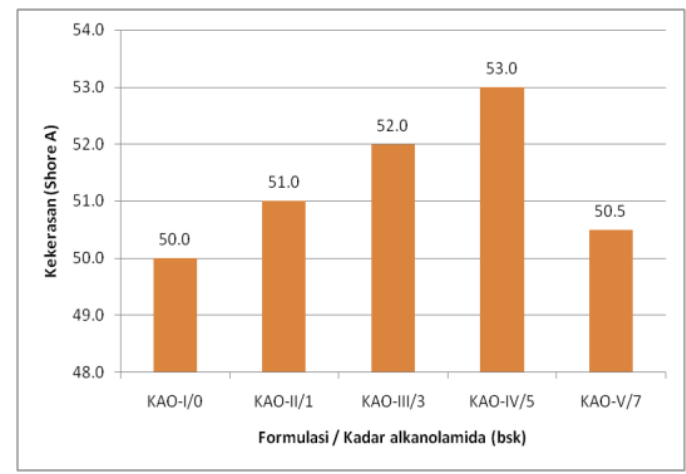

Gambar 3. Kekerasan vulkanisat karet alam berpengisi kaolin dan alkanolamida

Kompon karet alam berpengisi kaolin hingga 5,0 bsk menghasilkan vulkanisat karet alam berpengisi kaolin dan alkanolamida dengan kekerasan (hardness) yang lebih tinggi, dan menurun dengan penambahan alkanolamida lebih dari 5,0 bsk. Hal ini disebabkan jumlah/kadar yang lebih banyak dari alkanolamida tersebut membuat alkanolamida bertindak sebagai bahan yang dapat melarutkan bahan-bahan kuratif, sehingga menurunkan kerapatan sambung silang yang mungkin dibentuk. Penjelasan ini 
konsisten dengan nilai perbedaan Tork (Tork maksimum - Tork minimum) dari komponkompon karet alam berpengisi tersebut yang diperlihatkan pada tabel 2 .

\section{Kesimpulan}

Alkanolamida meningkatkan laju pematangan kompon karet alam berpengisi kaolin. Kekerasan dan kekerasan sambung silang dari vulkanisat karet berpengisi tersebut meningkat dengan ditambahkannya alkanolamida ke dalam kompon karet alam berpengisi kaolin hingga kadar 5,0 bsk., penambahan yang lebih banyak menyebabkan Kekerasan vulkanisat menjadi turun.

\section{Ucapan Terima Kasih}

Penulis mengucapkan terimakasih kepada Kepala Laboratorium Kimia Organik F-Mipa Usu dan kepada PT Karet Deli yang telah memberikan fasilitas sehingga penelitian dapat dilakukan.

\section{Daftar Pustaka}

[1] G. Kraus, Interactions of Elastomerad Reinforcing Fillers, Rubber Chem Technol, p 1070 - 1114, 1965.

[2] H. Ismail dan Hashim, A. S, Pengenalan Penyebatian dan Pemrosesan Getah, Penerbit Universiti Sains Malaysia, Pulau Pinang, Malaysia, 1998.

[3] H. L. Stephen, Rubber Technology, Van Nostrand Reinhold Company, New York, p. 19-50, 1973.

[4] Indra Surya, Pengaruh penambahan Bis (3trietoksisililpropil) tetrasulfida pada pengukuhan kaolin terhadap sifat-sifat uji tarik karet alam, Jurnal Teknologi Proses, Vol. 1 No. 1 Juli 2002.

[5] K. E. Polmanteer and Lentz, C. W., Reinforcing Studies - Effect of Silica Structure on Properties and Crosslink Density, Rubber Chem Technol, p 795-809, 1975.

[6] M. R. Silverstein, Spectrometric Identification of Organic Compounds, Fourth edition. p.166-170, John Wiley \& Son, New York, 1916. 